\title{
Cells perpetuating the inflammatory response in scleritis
}

\author{
Wolfgang Bernauer, Peter G Watson, Basil Daicker, Susan Lightman
}

\begin{abstract}
Scleritis can be a destructive disease frequently associated with autoimmune disorders. It is believed that primary vasculitis plays an important role in its pathogenesis, but little is known about the cellular effector mechanisms. The purpose of this study was to analyse the inflammatory cellular infiltrate in scleritis. Six episcleral biopsies and two enucleated eyes were studied. The episcleral biopsies were taken from patients with nodular scleritis. In one patient enucleation was done after perforation in anterior necrotising scleritis and, in the other after misdiagnosis of posterior scleritis as intraocular tumour. Morphological criteria and immunohistochemical methods were used to characterise the inflammatory cellular infiltrate. The inflammatory cells infiltrating the episcleral tissue were mainly $\mathbf{T}$ lymphocytes and macrophages. There was a predominance of $\mathrm{CD} 4$ positive cells, but only few lymphocytes were activated (expressed IL-2 receptor). The cells infiltrating the scleral fibres in the enucleated eyes consisted in both cases predominantly of $\mathbf{T}$ cells. Clusters of $B$ cells were found in perivascular areas. In circumscribed areas neutrophils, macrophages, and plasma cells were part of the scleral infiltrate. Signs of a granulomatous process with activated macrophages (epitheloid and giant cells) were present in necrotising scleritis. Expression of major histocompatibility class II molecules (MHC II) was found on lymphocytes and rarely on macrophages. Signs of primary vasculitis were not found in any of the specimens. The cellular infiltrate in scleritis shows, at least at certain stages, features compatible with a $\mathbf{T}$ cell mediated (autoimmune) disorder, which may have major therapeutic implications.

(BrF Ophthalmol 1994; 78: 381-385)
\end{abstract}

Scleritis can be a destructive disease, leading to the loss of the affected eye from severe pain, secondary destruction of uveal and retinal tissue, or even perforation of the globe. It can be classified clinically as anterior or posterior, and anterior scleritis subdivided as diffuse, nodular, or necrotising type of disease. ${ }^{1}$

Scleritis is occasionally caused directly by an infective agent, but the vast majority occur de novo without any obvious inciting agent (endogenous). Non-infectious scleritis is frequently associated with autoimmune disorders. ${ }^{12}$ Closure of episcleral and scleral vessels is seen clinically in necrotising scleritis, and abnormal vascular filling patterns were shown by fluorescein angiography in different forms of anterior scleritis. ${ }^{3}$ It is therefore likely that vascular or perivascular disease plays a role in the pathogenesis of scleral inflammation. Based on immunohistochemical findings ${ }^{45}$ there is a hypothesis that endogenous scleritis represents a local primary vasculitis initiated by circulating immune complexes (type III reaction of hypersensitivity).

The purpose of this study was to elucidate immune mechanisms in non-infectious scleritis by analysing the composition of the inflammatory cellular infiltrate in episcleral and/or scleral tissue. With an increased understanding of the mechanisms causing scleral disease, it will be possible to develop the rationale for the use of more specific immunosuppressive agents.

\section{Patients and methods}

\section{PATIENTS}

Six episcleral biopsies were studied in comparison with normal episclera, taken from 12 patients undergoing cataract surgery; furthermore, two enucleated eyes were examined.

\section{Cases 1-6}

The episcleral biopsies were taken after written consent from six patients (one man and five women) with nodular scleritis. They ranged in age from 41 to 61 years (mean 50 years). All patients underwent a clinical and immunological evaluation, revealing no underlying disease in five patients and rheumatoid arthritis in one patient. All the patients had active disease, three patients were untreated, two were on non-steroid anti-inflammatory agents (flurbiprofen) and the patient suffering from rheumatoid arthritis was taking $10 \mathrm{mg}$ of oral prednisone.

Case 7

This 83-year-old woman had a 2 year history of a painful left eye. When referred to an ophthalmologist, anterior necrotising scleritis was present and there was a scleral perforation. The eye was subsequently removed. Clinical and immunological examinations gave no evidence for rheumatoid arthritis or another underlying disease, and she was on no immunosuppressive treatment when the eye perforated.

\section{Case 8}

This 28-year-old woman had an 8 month history of a painful left eye, visual loss, and proptosis. Computed tomography of the orbit revealed thickening of the posterior sclera and the adjacent tissue. Therapy with systemic steroids was unsuccessful and stopped after 2 months. It was assumed that malignant neoplasia could be the 
cause of the 'tumour'. The blind eye, showing further increase of volume, signs of intraocular inflammation, and a totally detached retina, was removed 3 months later. No systemic disorder was detected.

\section{SPECIMENS}

The biopsy specimens were obtained after topical instillation of $1 \%$ tetracaine (Amethocaine) and perilesional subconjunctival injection of $2 \%$ lignocaine. The diseased tissue was taken from the clinically most inflamed area over the scleral nodule. Normal episclera was taken, after written consent, during cataract surgery. The specimens were immediately fixed in acetone plus inhibitors (2 $\mathrm{mM}$ phenylmethylsulphonylfluoride and $20 \mathrm{mM}$ iodoacetamide) overnight at $-20^{\circ} \mathrm{C}$. They were then embedded in glycol methacrylate and stored at $-20^{\circ} \mathrm{C}$.

The two enucleated eyes were fixed in $4 \%$ buffered formalin and embedded in paraffin.

\section{HISTOPATHOLOGY}

Episcleral specimens ( $1.5 \mu \mathrm{m}$ sections) and $3 \mu \mathrm{m}$ sections of the enucleated eyes were studied, all stained with haematoxylin and eosin.

\section{IMMUNOHISTOCHEMICAL STAINING}

The glycol methacrylate embedded tissue was cut into $1.5 \mu \mathrm{m}$ serial sections and immunohistochemical staining performed using the avidin biotin complex (ABC) method, as previously described by us. ${ }^{6}$ In brief, after blocking of endogenous peroxide activity, slides were washed in TRIS buffered saline (TBS) and incubated for $\mathbf{3 0}$ minutes with culture medium ( $20 \%$ fetal calf serum, $1 \%$ bovine albumin). Appropriately diluted anti-human antibody was placed on each tissue section. These were then incubated overnight in a moist chamber. Slides were washed in TBS and biotinylated secondary antibodies applied. After washing in TBS, ABC was applied for 2 hours. After washing in TBS, aminoethylcarbazole was used to give a red final reaction product, and slides were counterstained with haematoxylin.

Serial sections of the paraffin embedded globes were cut, $3 \mu \mathrm{m}$ thick, they were dewaxed with toluene and graded alcohols, and a slight modification (shorter incubation time) of the above mentioned immunohistochemical staining technique was applied.

The following primary antibodies were used on the glycol methacrylate embedded sections: Anti-CD3 (Dako, High Wycombe, Bucks, UK) for T lymphocytes; anti-CD4 (Becton Dickinson, Oxford, UK) for CD4-positive lymphocytes ('helper/inducer'); anti-CD8 (Dako) for CD8positive lymphocytes ('cytotoxic'); anti-IL2R (Dako) for activated $\mathrm{T}$ lymphocytes bearing interleukin 2 receptors; anti-CD20 (Dako) for B lymphocytes; HLA-DR (Dako) for the expression of class II major histocompatibility molecules; anti-CD68 (Dako) for monocytes/ macrophages; anti-IgG (Hoechst-Boehring, 92500 Reuil-Malmaison, France); and anti-C3 (Hoechst-Boehring) to study immunoglobulins and complement components in the vessel walls.

On the formalin fixed (paraffin embedded) sections the following antibodies were used: anti-CD3 (Dako) for T lymphocytes; OPD4 (Dako) for the CD4 positive $\mathrm{T}$ lymphocyte subset; anti-CD20 (Dako) for B lymphocytes; MT-2 (Dako) for the expression of class II major histocompatibility molecules; MAC387 (Dako) for monocytes/macrophages; anti-IgG (HoechstBoehring) and anti-C3 (Hoechst-Boehring) to study immunoglobulins and complement components in the vesssel walls; and BMA-120/QBend 10 (Hoechst-Boehring) to assess endothelial integrity.

Sections without the primary antibodies (negative controls) and tissue sections of lymphoid tissue (positive controls) served as experimental controls.

\section{ANALYSIS}

Morphological criteria and immunohistochemical methods were used to characterise the inflammatory cellular infiltrate and to assess the presence of vasculitis. Primary vasculitis was defined as neutrophil invasion of the vessel wall, with fibrinoid necrosis revealed by light microscopy. ${ }^{7}$ Sections of normal episclera (taken from patients undergoing cataract surgery, embedded into glycol methacrylate, and processed as outlined above) were compared with diseases episcleral tissue. The differences in the cellular infiltrate between normal and diseased episclera were quantified by cell counts in three representative high power fields $(\times 400)$ in the deep conjunctival substantia propria. Unaffected sclera and episclera of a formalin fixed and paraffin embedded enucleated eye (control) were compared with the globes affected by scleritis.

\section{Results}

\section{CONTROLS}

The cell counts in deep normal conjunctival substantia propria are listed in Table 1. Studies of normal, extravascular sclera showed very occasional T cells, and no other cell types were detected by the monoclonal antibodies.

\section{THE EPISCLERA IN NODULAR SCLERITIS \\ (CASES 1-6)}

The density of the cellular infiltrate varied greatly among the specimens. Significant changes in the distribution of cells infiltrating the deep conjunctival lamina propria were found in the number of macrophages (CD68) (Fig 1), T lymphocytes (CD3), and MHC II molecule (HLA-DR) expressing cells. The results are shown in detail in Table 1.

The increase in the mean number of $T$ cells was 14 times higher in the episclera of scleritis patients over normal controls. There were significantly increased numbers of CD4 and CD8 positive $T$ cells. The CD4/CD8 ratio was $1 \cdot 3$. The number of activate $T$ cells was small and not significantly increased over normal controls. Cells expressing MHC II molecules (HLA-DR) were lymphocytes and some macrophages. No 
Table 1 Enumeration of mononuclear cell populations in the deep conjunctival substantia propria of nodular scleritis and normal controls (mean cell count/ $\mathrm{mm}^{2}(S E M)$ )

\begin{tabular}{llll}
\hline Antibody & Specificity & Normals $(n=12)$ & Nodular scleritis $(n=6)$ \\
\hline Lymphocytes: & & & \\
Anti-CD3 & Pan T cell marker & $2 \cdot 4(2 \cdot 9)$ & $32 \cdot 9(18 \cdot 7)^{\star}$ \\
Anti-CD4 & CD4 positive lymphocytes & $0 \cdot 8(0 \cdot 8)$ & $17 \cdot 2(12 \cdot 2)^{\star}$ \\
Anti-CD8 & CD8 positive lymphocytes & $0 \cdot 9(0 \cdot 9)$ & $12 \cdot 9(10 \cdot 4)$ \\
Anti-IL-2R & IL-2 receptor expressing cells & $0 \cdot 1(0 \cdot 1)$ & $2 \cdot 2(2 \cdot 1)$ \\
Anti-CD20 & B cells & $0(0)$ & $0 \cdot 7(0 \cdot 7)$ \\
Others: & & $2 \cdot 5(2 \cdot 2)$ & $26 \cdot 6(16 \cdot 0)^{\star}$ \\
Anti-CD68 & Macrophages & $5 \cdot 1(2 \cdot 9)$ & $65 \cdot 6(41 \cdot 1)^{\star}$ \\
Anti HLA-DR & MHC II molecules & &
\end{tabular}

${ }^{\star} \mathrm{p}<0.05$, by the Mann-Whitney $\mathrm{U}$ test in comparison with normal controls.

significant differences were found in the number of B cells (CD20) between patients with scleritis and normal controls. Neutrophils, as identified by morphological criteria, were only found occasionally.

No signs of granulomatous inflammation or signs of primary vasculitis were found in these specimens. There was widespread staining for IgG and C3, but there were no deposits of these immunoreactants (complement fragments) in the vessel wall.

Figure 1 Nodular scleritis. Abundance of macrophages in the conjunctival substantia propria. (Glycol methacrylate embedded section; anti-CD68 antibody, immunoperoxidase reaction, magnification $\times 300$.)

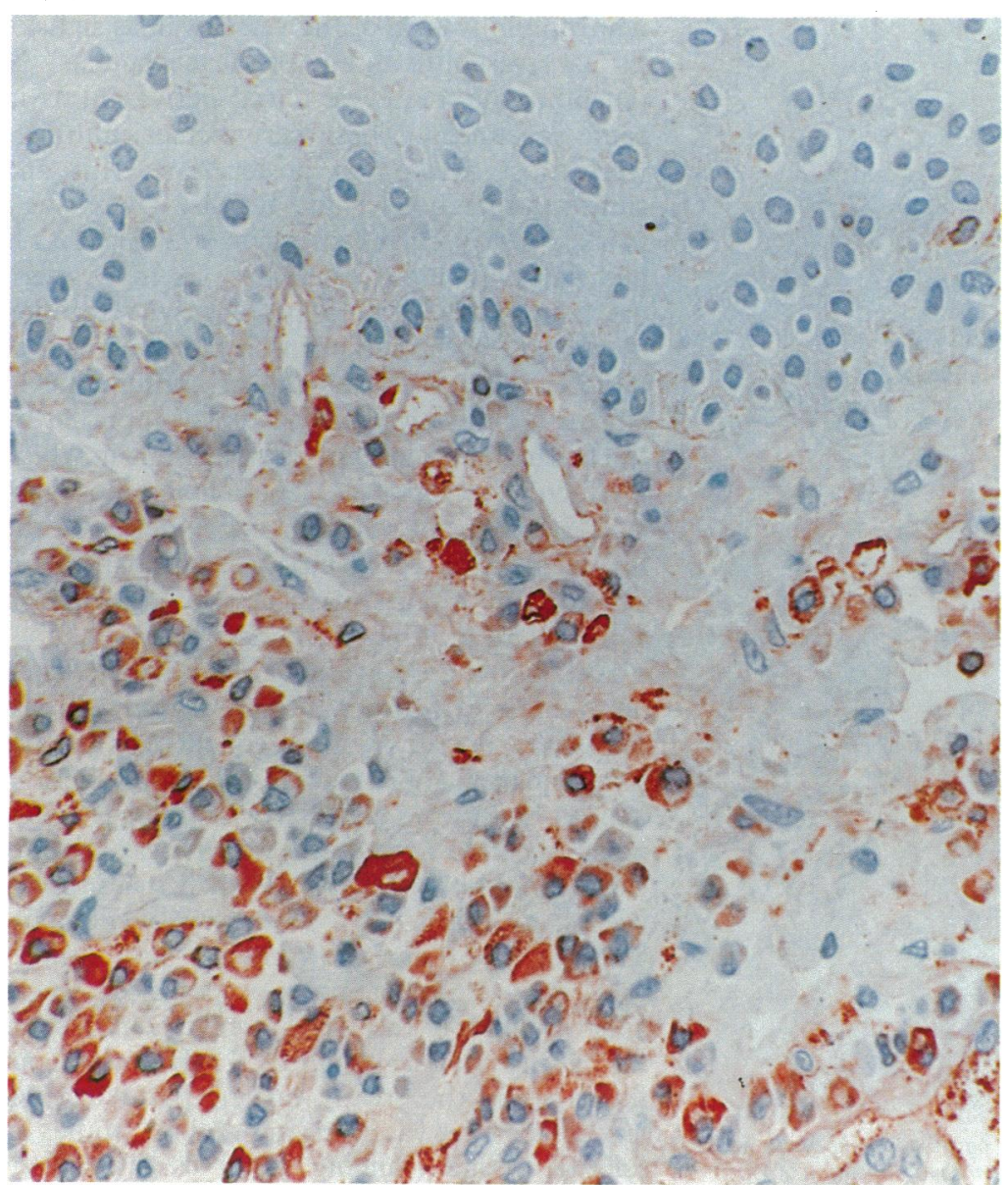

THE EPISCLERA AND SCLERA IN NECROTISING ANTERIOR SCLERITIS (CASE 7)

Pathological examination of the globe showed hyperaemia of the episclera and a scleral perforation in the pre-equatorial zone at 11 o'clock. The retina was totally detached, and there was a choroidal detachment with haemorrhage.

\section{Histological observations}

The episcleral tissue and the anterior sclera adjacent to the lesion showed increased thickness and an intense inflammatory reaction. Granulomatous inflammation (Fig 2) but no vasculitis was found in the affected sclera. The area of scleral perforation was filled with vitreous, containing a mixed cellular infiltrate.

The composition of the cellular infiltrate in the episclera was similar to that found in nodular scleritis (cases 1-6). The scleral cellular infiltrate consisted of a mixture of inflammatory cells: plasma cells and macrophages dominated near to the scleral defect. Debris with activated macrophages (epitheloid cells), giant cells, and lymphocytes formed granulomata. The lymphocytes involved in granuloma formation and the cells infiltrating the scleral fibres distal to the lesion were $T$ cells (CD3) (Fig 2). T cells together with few B lymphocytes (CD20) were found densely packed around episcleral and scleral vessels, but not in the vessel walls. CD4 cells were observed only occasionally. MHC class II expression was frequently found on lymphocytes, and to a lesser extent on macrophages or fibroblasts. Fibroblasts were a frequent finding distal to the advancing lesion.

\section{THE EPISCLERA AND}

Pathological examination of the globe showed moderate and excessive thickening of the episclera and sclera (up to $6 \mathrm{~mm}$ ), respectively. There was a serous detachment of the retina.

Microscopy revealed that the thickening of the sclera was caused mainly by newly formed sclera collagen and the cellular infiltrate. The posterior episclera and thickened sclera were infiltrated by mononuclear inflammatory cells. No signs of granulomatous inflammation were present. Primary vasculitis, as defined above, was absent. No immunoreactant deposits (immunoglobulin, complemented fragments) in the vessel wall or disrupted endothelium (as identified with the antibodies BMA-120 and QBend 10), both signs of vasculitic disease, were seen.

The cellular infiltrate in the posterior episclera and sclera consisted mainly of $T$ lymphocytes (CD3) and fibroblasts, to a lesser extent of plasma cells and macrophages (as identified with MAC387). The predominant cells infiltrating the scleral fibres were T lymphocytes (Fig 3). Many of them were CD4 cells, as identified by the antibody OPD4 (Fig 4). More prominent than in necrotising scleritis (case 7) was the finding of perivascular accumulations of lymphocytes in both the sclera and episclera. These accumulations consisted mainly of B (CD20) and T cells. In the perivascular area there was also a marked expression of MHC class II molecules on lymphocytes and occasionally on macrophages (Fig 5).

\section{Discussion}

This study investigated the spectrum of inflammatory cells in episcleral and/or scleral tissue using morphological criteria and immunohistochemical methods. By analysing ocular tis- 
sue of patients with uncontrolled disease we hoped to determine some of the immune mechanisms involved in non-infectious scleritis.

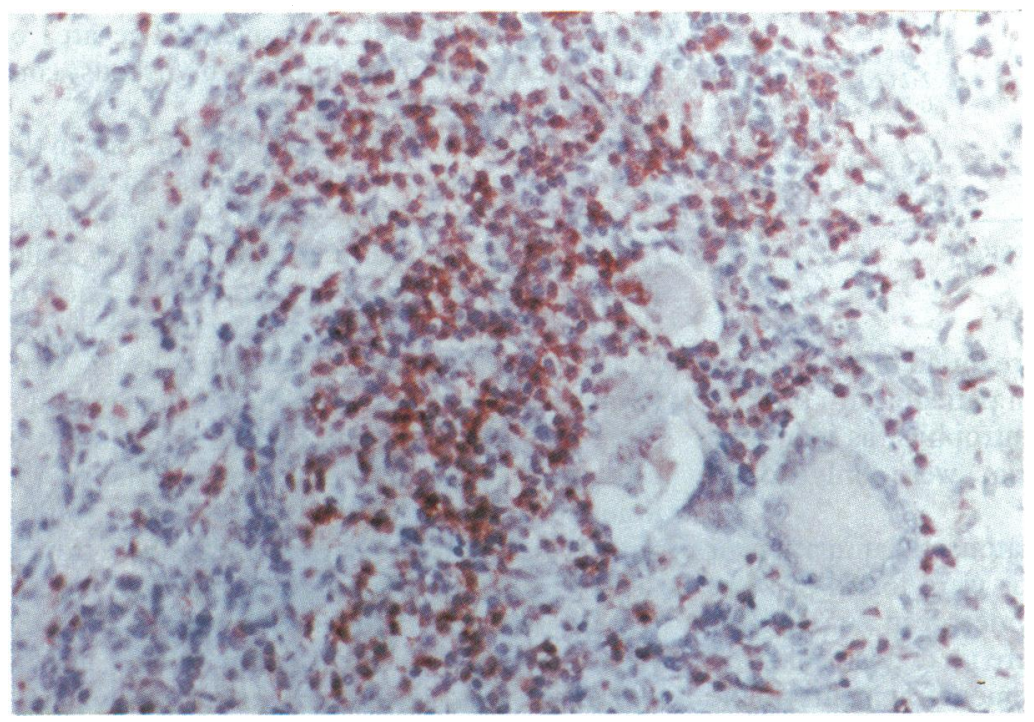

Figure 2 Granulomatous inflammation in necrotising scleritis. Epithelioid and giant cells are surrounded by a dense infiltrate of $T$ cells. (Formalin fixed tissue; anti-CD3 antibody, immunoperoxidase reaction, magnification $\times 47$.)

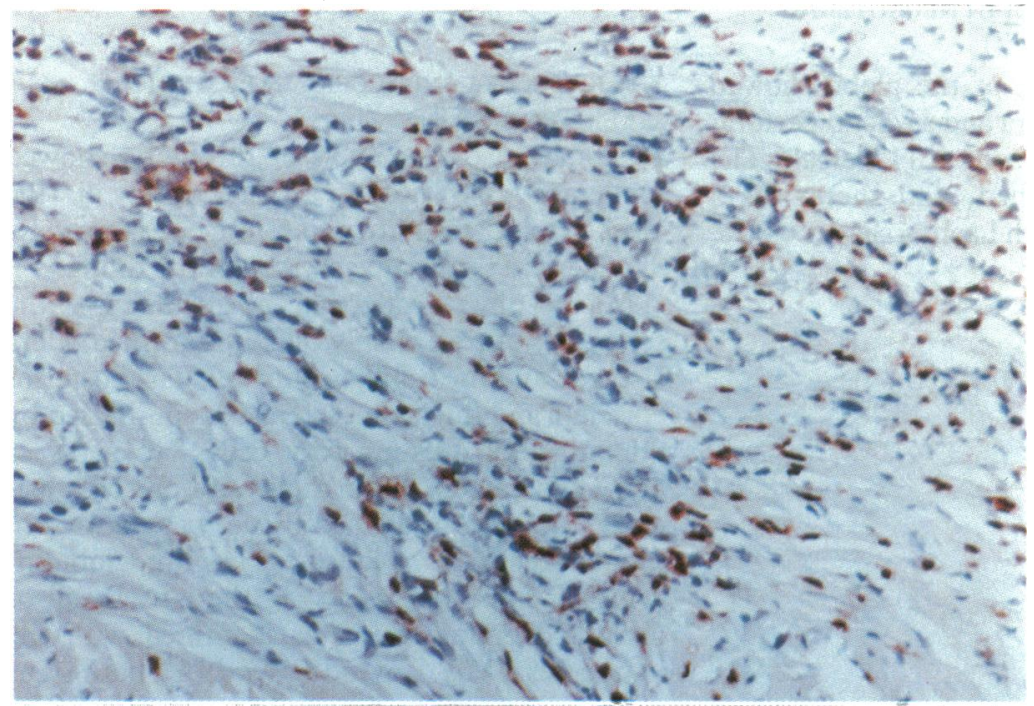

Figure 3 Posterior scleritis. The scleral fibres are predominantly infiltrated by $T$ cells. (Formalin fixed tissue; anti-CD3 antibody, immunoperoxidase reaction, magnification $\times 47$.)

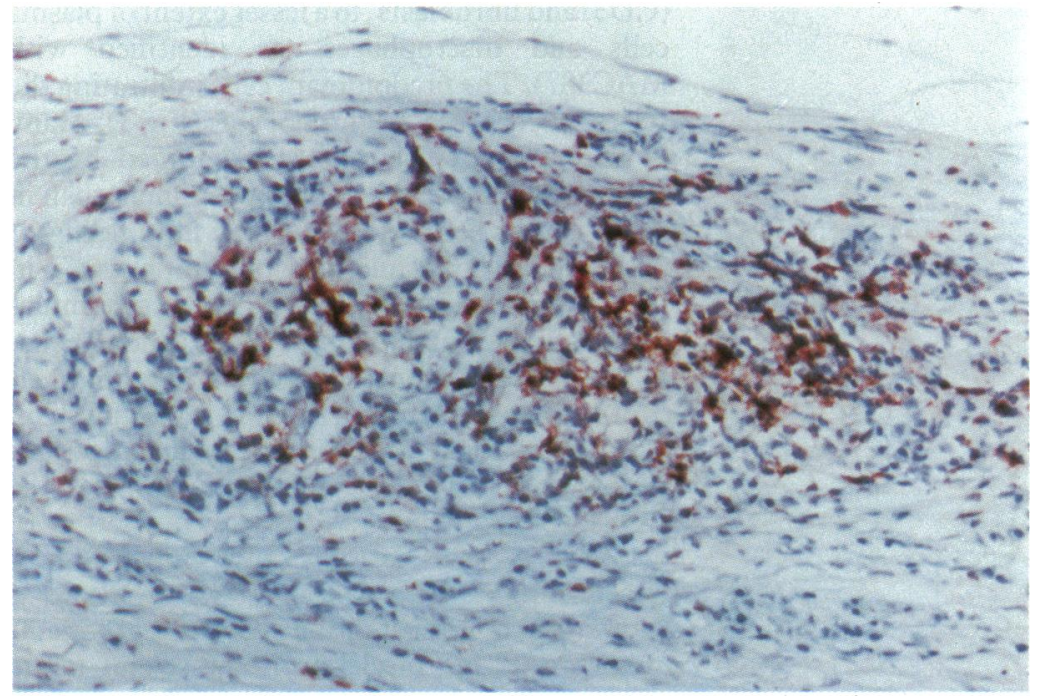

Figure 4 Posterior scleritis. Perivascular accumulation of CD4 positive lymphocytes. (Formalin fixed tissue; OPD4 antibody, immunoperoxidase reaction, magnification $\times 47$.)
This study agrees with previous investigators $^{4-10}$ who found that the cellular infiltrate in scleritis consists largely of lymphocytes and to a lesser extent macrophages, plasma, and giant cells. ${ }^{811}$ In addition to conventional histopathology, a phenotypical analysis of the lymphocytes, using monoclonal antibodies, was performed to allow conclusions on the role of these cells in scleral disease. An earlier immunopathological study in treated patients with necrotising scleritis ${ }^{5}$ had shown increased numbers of $\mathrm{T}$ cells and macrophages in the sclera and immune complex mediated vasculitis in the large majority of specimens.

The abundance of lymphocytes was confirmed by our study, and immunohistochemical analysis revealed that more than $90 \%$ of them were $\mathrm{T}$ cells. T lymphocytes were the predominant cells in the episclera of nodular scleritis, and infiltrated the scleral fibres distal to the lesion in necrotising scleritis. They were also the predominant cells infiltrating the thickened sclera and episclera in posterior scleritis. Of the $T$ cell subsets, CD4 positive cells were numerous in the episclera of nodular scleritis and posterior scleritis. The presence of MHC class II expressing cells indicates the potential to present local antigens to these infiltrating CD4 positive cells. Activated lymphocytes (expressing the interleukin 2 receptor) were only found in a small number in nodular scleritis. Owing to the tissue fixation in formalin the anti-IL-2R antibody was not used in the enucleated eyes.

Since scleritis is associated with altered vascular filling patterns, ${ }^{3}$ special attention was given to the vascular and perivascular findings. We were unable to identify fibrinoid necrosis and neutrophil invasion of the vessel wall as signs of primary vasculitis in any of our specimens. As did other authors ${ }^{811}$ we found perivasculitis in some specimens. These perivascular infiltrates were most marked in posterior scleritis and consisted mainly of $T$ and B cells. There was a marked perivascular expression of $\mathrm{MHC}$ class II molecules. It might, therefore, be that a perivascular delayed type hypersensitivity reaction plays a role in the pathogenesis of some forms of scleritis. That $\mathrm{T}$ cell dependent immune mechanisms are involved in scleritis is supported by the finding of granulomatous reactions in which activated macrophages (epithelioid and giant cells) play a major role. Further evidence for the involvement of $\mathrm{T}$ cell mediated mechanisms is provided by reports of successful treatment of active scleritis with cyclosporin A. ${ }^{12-14}$

Although there is evidence of a $\mathrm{T}$ cell mediated (autoimmune) disorder at some stage of scleritis, our study does not allow conclusions on the initiating mechanisms of non-infectious scleritis. This is due to the fact that when biopsy specimens are investigated, the disease has already existed for some time, and it is likely that primary events are masked by secondary phenomena. The $\mathrm{T}$ cell response shown in this study, therefore, may represent only a perpetuation mechanism, similar to the $T$ cell involvement in some forms of systemic vasculitis. ${ }^{15-17}$ However, our findings and the greatly varying frequencies of leucocytoclastic vasculitis in previous studies on scleritis tissue (ranging from $0 \%^{8}$ to $75 \%{ }^{5}$ ) 


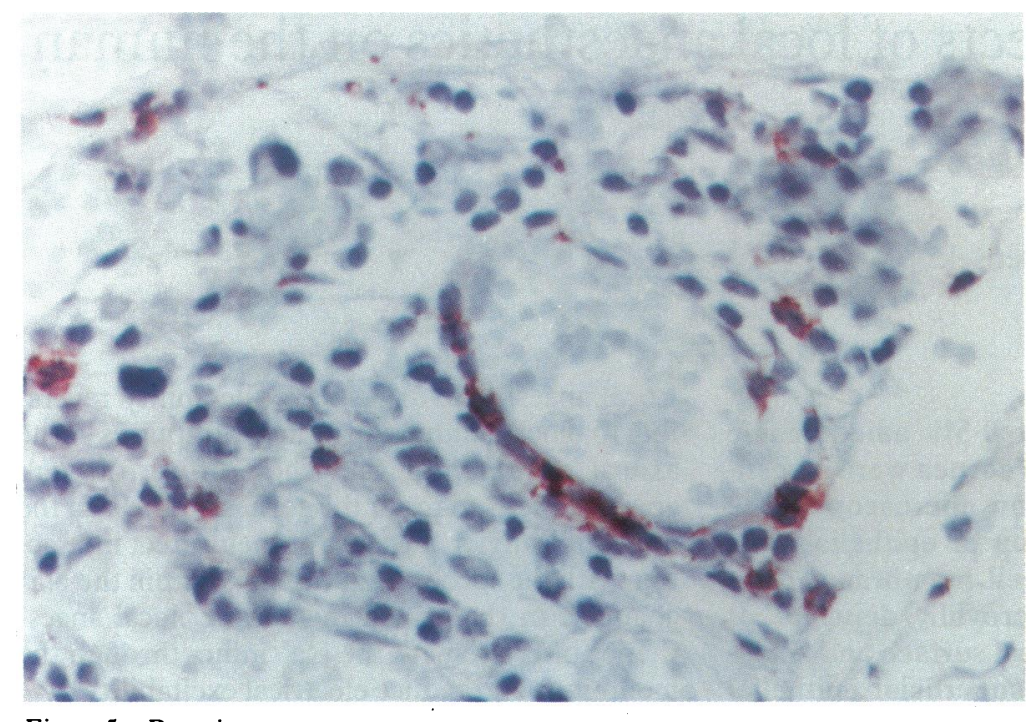

Figure 5 Posterior scleritis, similar area to Figure 4. Notice the perivascular expression of MHC class II molecules on lymphocytes and occasionally on macrophages. (Formalin fixed tissue; antibody $M T-2$ immunoperoxidase reaction, magnification $\times 117$. suggest that different pathomechanisms are involved in scleral inflammation..$^{18}$ Non-necrotising disease may represent a delayed type of hypersensitivity reaction, whereas some forms of necrotising disease are probably initiated by a primary vasculitis.

In summary, we have shown that the cellular infiltrate in non-infectious scleritis shows features of a $\mathrm{T}$ cell mediated (autoimmune) disorder. Despite the uncertainty as to whether the $T$ cell response is restricted to the perpetuation of this inflammation or whether autoreactive $T$ cells are involved in its initiation, our findings offer justification for involving $\mathrm{T}$ cell specific immunosuppressive agents, such as cyclosporin $\mathrm{A}$ or FK506, in the treatment of scleral inflammation.
This study was supported in part by the Swiss National Science Foundation, the Foundation Florian Verrey, the Swiss Foundation to Prevent Blindness, and by a locally organised research scheme from Moorfields Eye Hospital.

1 Watson PG, Heyreh SS. Scleritis and episcleritis. $\mathrm{Br} \mathcal{F}$ Ophthalmol 1976; 60: 163-91.

2 Watson PG. Diseases of the sclera and episclera. In: Duane TD, Jaeger EA, eds. Clinical ophthalmology. Vol 4. Philadelphia: Lippincott, 1988: Chapter 23, 1-43.

3 Watson PG, Bovey E. Anterior segment fluorescein angiography in the diagnosis of scleral inflammation. Ophthalmology 1985; 92: 1-11.

4 Rao NA, Marak GE, Hidayat AA. Necrotizing scleritis. A clinico-pathologic study of 41 cases. Ophthalmology 1985; 92 . 1542-9.

5 Fong LP, de la Maza MS, Rice BA, Kupferman AE, Foster CS. Immunopathology of scleritis. Ophthalmology 1991; 98: 472-9.

6 Bernauer W, Wright P, Dart JK, Leonard J, Lightman S. The conjunctiva in acute and chronic mucous membrane pemphigoid. An immunohistochemical analysis. Ophthalmology 1993; 100: 339-46.

7 Robbins SL, Kumar V. Basic pathology. Philadelphia: Saunders, 1987: 296

8 Young RD, Watson PG. Microscopical studies of necrotizing scleritis. I. Cellular aspects. Br f Ophthalmol 1984; 68: 77080.

9 Sevel D. Necrogranulomatous scleritis. Clinical and histological features. Am f Ophthalmol 1967; 64: 1125-34.

10 De la Maza MS, Foster CS. Necrotizing scleritis after ocular surgery. Ophthalmology 1991; 98: 1720-6.

11 Benson WE. Posterior scleritis. Surv Ophthalmol 1988; 32 297-316.

12 Hakin KN, Ham J, Lightman SL. Use of cyclosporin in the management of steroid dependent non-necrotising scleritis. Br f Ophthalmol 1991; 75: 340-1.

13 Wakefield D, McCluskey P. Cyclosporin therapy for severe scleritis. Brf Ophthalmol 1989; 73: 743-6.

14 McCarthy JM, Dubord PJ, Chalmers A, Kassen BO, Rangno KK. Cyclosporin A for the treatment of necrotizing scleritis KK. Cyclosporin A for the treatment of necrotizing scleritis 7 Rheumatol 1992; 19: 1358-61.

15 Kallenberg CGM, Cohen Tervaert JW, van der Woude FJ Goldschmeding $R$, von dem Borne AEGKr, Weening JJ Autoimmunity to lysosomal enzymes: new clues to vasculitis and glomerulonephritis? Immunol Today 1991; 12: 61-4.

16 Mathieson PW, Cobbold SP, Hale G, Clark MR, Oliveir DBG, Lockwood CM, et al. Monoclonal-antibody therapy in systemic vasculitis. N Engl f Med 1990; 323: 250-4.

17 Jenette CJ, Wiolkman AS, Falk RJ. Anti-neutrophil cytoplasmic autoantibody-associated glomerulonephritis and vasculitis. Am $\mathcal{F}$ Path 1989; 135: 921-30.

18 Mondino BJ Discussion of: Rao NA, Marak GE, Hidayat AA Ophthalmology 1985; 92: 1548-9. 